\title{
Anaesthetic Management of Patients with Takayasu's Arteritis for Open Cholecystectomy: a Report of Two Cases
}

\author{
Gentle Sunder Shrestha, ${ }^{1}$ Ninadini Shrestha, ${ }^{1}$ Battu Kumar Shrestha, ${ }^{2}$ Pramesh Sunder Shrestha' \\ 'Department of Anesthesiology, IOM, Tribhuwan University Teaching Hospital, Kathmandu, ${ }^{2}$ Department of Anesthesiology, Sahid \\ Gangalal National Heart Center, Kathmandu, Nepal.
}

\section{ABSTRACT}

Takayasu's arteritis is a well known yet rare form of large vessel vasculitis. ${ }^{1}$ This inflammatory disease often affects the ascending aorta and aortic arch, causing obstruction of the aorta and its major arteries. ${ }^{2}$ Anaesthetic management for these patients is complicated by severe hypertension, end-organ dysfunction, stenosis of major blood vessles and difficulties in monitoring blood pressure. ${ }^{1}$ We present two patients who underwent open cholecystectomy under neuraxial anaesthesia. We have discussed about various perioperative issues and their management.

Keywords: anaesthetic management; takayasu's arteritis.

\section{INTRODUCTION}

Takayasu's arteritis (TA) is a rare, chronic progressive panendarteritis involving the aorta and its main branches, leading to stenosis, thrombosis and the formation of aneurysms. Hence it is also known as aortic arch syndrome or pulseless disease. The major clinical finding is loss of palpable pulses in the upper limbs and neck. It has female predilection and involves mainly the Asians. ${ }^{3}$ There are anaesthetic implications of this disease as it involves the vascular system leading to involvement of various organs. We present the successful anaesthetic management of two cases undergoing elective open cholecystectomy under regional anaesthesia.

\section{CASE REPORT}

\section{First case}

A 28 years old lady, a known case of symptomatic cholelithiasis, presented with on and off right upper quadrant pain for last six months. She was a diagnosed case of Takayasu's arteritis for last six years, on treatment with oral Prednisolone $20 \mathrm{mg}$ daily. She was taking tablet Amlodipine $5 \mathrm{mg}$ daily for hypertension since last six months.

Preoperative physical examination revealed impalpable bilateral radial, brachial and carotid pulses. Her bilateral lower limb pulses were palpable. Her blood pressure was $180 / 80 \mathrm{mmHg}$ at her right leg. Other physical examination findings were normal. Laboratory investigation reports including ECG and chest X-ray were normal. CT angiogram of aortic arch and arch vessels showed critical stenosis (near total occlusion) of whole of right brachiocephalic trunk and right common carotid artery and whole of left common carotid artery.

Surgery was planned under epidural anaesthesia. Right posterior tibial artery was cannulated for invasive arterial blood pressure monitoring. Epidural catheter was inserted at $\mathrm{T}_{8-9}$ interspace and $3 \mathrm{ml}$ of $2 \%$ lignocaine with adrenaline was given as test dose. Epidural was activated with $0.5 \%$ Bupivacaine $5 \mathrm{ml}$ and Morphine 2 $\mathrm{ml}(2 \mathrm{mg})$. Level of block was obtained from $T_{2}$ to $T_{10}$ dermatome. Hydrocortisone $25 \mathrm{mg}$ IV was administered for perioperative steroid supplementation. Surgery was started. Oxygen was supplemented via face mask at 5 $\mathrm{L} / \mathrm{min}$. Intraopervatively $10 \mathrm{ml}$ of $0.25 \%$ Bupivacaine was sprinkled between liver and diaphragm. After half an hour of starting of surgery, $0.25 \%$ of Bupivacaine infusion was started via epidural catheter at $6 \mathrm{ml} /$ hour. Intraoperative course was uneventful with intact

Correspondence: Dr. Gentle Sunder Shrestha, Department of Anesthesiology, IOM, Tribhuwan University Teaching Hospital, Kathmandu, Nepal. Email: gentlesunder@hotmail.com , Phone: +977-9841248584. 
neurological status monitored clinically. Total duration of surgery was one and half hour. Post operative epidural analgesia was administered with continuous infusion of $0.125 \%$ Bupivacaine and $2 \mathrm{mcg} / \mathrm{ml}$ Fentanyl combination at $6 \mathrm{ml} /$ hour. Epidural catheter was removed on third postoperative day. She had uneventful postoperative period and was discharged home on fourth postoperative day.

\section{Second case}

A 33 years old female, a case of symptomatic cholelithiasis, presented with right upper abdominal pain for 3 months. She was diagnosed case of Takayasu's arteritis 11 years back when she presented with fatigue and discomfort of upper extermity muscles while in use, absence of pulse in upper limbs, syncope, hypertension, dyspnea and palpitation. She was on treatment with oral Prednisolone, Amlodipine, Atenolol, Hydrochlorothiazide and Enalapril.

On, physical examination, all peripheral pulses were palpable, blood pressure was $140 / 90 \mathrm{~mm} \mathrm{Hg}$ in upper limb and diastolic murmur was appreciable on auscultation of precordium which was most marked in aotic area. Echocardiography revealed severe aortic regurgitation. Carotid Doppler showed 20\% stenosis of left carotid artery.

After routine preoperative preparation and infective endocarditis prophylaxis with injectable Ampicillin $2 \mathrm{gm}$ and Gentamicin $80 \mathrm{mg}$, right radial artery was cannulated for continuous invasive arterial blood pressure monitoring. Epidural catheter was inserted at $\mathrm{T}_{9}{ }^{-}{ }_{10}$ interspace and $3 \mathrm{ml}$ of $2 \%$ lignocaine with adrenaline was given as test dose. Subarachnoid block was given at $\mathrm{L}_{3-4}$ space with $3 \mathrm{ml}$ of hyperbaric bupivacaine $0.5 \%$ and Fentanyl $0.5 \mathrm{ml}(25 \mathrm{mcg})$. Sensory block upto $\mathrm{T}_{4}$ dermatome with Bromage grade IV motor block was attained. Surgery was initiated. Total of $7 \mathrm{ml}$ of $2 \%$ lignocaine was topped up through epidural catheter during 1 hour 10 minutes of surgery. One episode of hypotension was treated with fluid bolus and Mephentermine $6 \mathrm{mg}$. Patient was intact neurologically, which was assessed clinically. Postoperative analgesia was attained with continuous infusion of $0.1 \%$ Bupivacaine and Fentanyl $2 \mathrm{mcg} / \mathrm{ml}$ at $5 \mathrm{ml} /$ hour. Postoperative course was uneventful. Epidural catheter was removed on third postoperative day and patient was discharged home on fifth postoperative day.

\section{DISCUSSION}

Takayasu's arteritis is an uncommon vasculitis characterized by a focal stenosis of the arterial lumen leading to distal ischemia and loss of pulse distal to the site of the lesion. It is more common in women of reproductive period. The exact etiology remains unknown but it may have an autoimmune basis. The disease initially have preocclusive phase of rheumatic or systemic symptoms. This is followed by occlusive phase with segmental arterial involvement in several sites. ${ }^{4}$ The disease is rarely diagnosed in preocclusive phase. Takayasu's arteritis is classified on the basis of distribution of affected vessels. Type I involves the aortic arch and its main branches. Lesions in type II are restricted to the descending thoracic and abdominal aorta. Patients with Type III show features of both types I and II. Patients with type IV show additional involvement of the pulmonary artery. ${ }^{5}$ Ishikawa graded Takayasu's arteritis based on presence of four major complications i.e., hypertension, retinopathy, aneurysm formation, and aortic regurgitation. In stage I, none of these complications were present, stage lla patients had only one of these (in a milder form), stage Ilb had only one of these complications but a rather severe one, and in stage III more than one complications were present. ${ }^{6}$

Both of our patients were female with mean age of 30.5 years. Both of them were hypertensive. One of them developed aortic regurgitation. However, neither of them have retinopathy or aneurysm formation. Hence both of them were of type I. According to Ishikawa grading, first case was in stage Ilb while the second case was in stage III.

Hypertension is the major complication affecting anaesthetic management. It is commonly renovascular in origin. ${ }^{7}$ Hypertension also results from reduced elasticity, narrowing of aorta and major arteries and abnormal function of carotid and aortic sinus baroreceptors. These patients often require multidrug treatment. If remain uncontrolled, they may require surgical management.

Various anaesthetic techniques have been implicated. The choice of regional versus general anaesthesia depends upon patient's general condition and types of surgery. There are reports of use of regional anaesthesia and analgesia as an adjuvant to general anaesthesia. The main concern during conduction of anaesthesia in patients with TA is the maintenance of blood pressure during the perioperative period.

General anaesthesia may result in wide swings in blood pressure like during endotracheal intubation and extubation or due to inadequate depth of anaesthesia. These periodic surges in blood pressure may result in cerebral haemorrhage, infarction or myocardial dysfunction. There are reports of successful surgery under general anaesthesia with different intraoperative neurological monitorings. ${ }^{8,9,10,11}$ However, there are also reports of uncomplicated neurological outcomes in which general anaesthesia was used without specialized 
neurological monitoring. ${ }^{12,13,14}$ There was one report of postoperative cerebral dysfunction. ${ }^{15}$

Regional anaesthesia may be advantageous in terms of neurological monitoring as awake patients provides reliable monitor of cerebral perfusion. However, it may be associated with hypotension, further compromising regional perfusion in the presence of preexisting stenosed vessels. Epidural anaesthesia is preferred over spinal anaesthesia as it is associated with gradual onset of sympathetic block and a gradual decrease in blood pressure. Measures to attenuate regional anaesthesia induced hypotension like prehydration with crystalloid, slow administration of local anaesthetics and titration of the local anaesthetics to the desired level avoid precipitous decrease in blood pressure. Hypotension can be treated with infusion of fluids, Trendelenburg position and intravenous ephedrine. It is best to avoid vasopressors in patients with preexisting compromised organ perfusion.

In both cases we chose regional anaesthesia. Both cases were similar in terms of type of surgery and involvement of carotid artery. As stated earlier, regional anaesthesia is advantageous in terms of neurological monitoring. Further, different neurological monitoring were not available in our setup. In the first case, epidural anaesthesia was used alone. There was severe carotid occlusion bilaterally and small haemodynamic compromise may lead to neurological impairment. So we decided to titrate anaesthetics gradually to the desired level and neurological assessment was done clinically. In second case we used combined epidural and spinal anaesthesia. Low dose combined spinal-epidural technique combines the reliability of intrathecal block and flexibility of epidural anaesthesia. It helps to deliver titrable anaestheisa with stable haemodynamics. ${ }^{16}$ Combined epidural spinal anaesthesia was found to provide superior analgesia and surgical conditions when compared with epidural technique alone. ${ }^{17}$ Further, Shrestha GS et al have reported a case describing the safety and efficacy of combined epidural spinal in a patient of dermatomysitis with valvular heart disease undergoing total abdominal hysterectomy. ${ }^{18}$

There may be other problems complicating the anaesthetic management. Cardiac dysfunction, if present is mainly because of hypertension. Some may have occlusive changes in coronary arteries leading to myocardial ischemia. If there is involvement of renal artery, they may have feature of renal dysfunction. They should be evaluated for Cushingoid features preoperatively as they often receive chronic steroid therapy. These patient require perioperative steroid supplementation.

Blood pressure monitoring can sometimes be challenging. If there is palbable peripheral pulses, noninvasive blood pressure monitoring, usually oscillometric method, can be used. Most of the times upper limb blood pressure correlates with lower limb blood pressure. There were reports with significant difference in arterial pressure between upper and lower limbs (more than $20 \mathrm{mmHg}$ ). ${ }^{19,20}$ These patients require blood pressure monitoring in both upper and lower limb. There patients required cautious use of regional anaesthesia. In patients with weak or absent peripheral pulses, other measures like pulse oximetry, automated non-invasive blood pressure monitoring and Doppler flow signals can be used to record blood pressure. In our first case, pulses were not palpable in upper extremities. She had developed cushingoid features due to long term use of steroid. The available non-invasive blood pressure cuffs were not of appropriate size to record her lower limb blood pressure. So we decided to cannulate her posterior tibial artery for blood pressure recording. In second case, though she had palpable pulses in the upper extremity, we opted for invasive blood pressure recording because of cardiac involvement.

In conclusion, Takayasu's arteritis with multisystem involvement may complicate anaesthetic management. Maintenance of adequate perfusion pressure is crucial during the procedure. Intraoperative neurologic monitoring should be considered in patients with carotid artery involvement. Cautiously performed neuraxial anaesthesia can be safe and effective in patients with Takayasu's arteritis with carotid involvement, with the provision of intraoperative clinical neurological monitoring and postoperative analgesia.

\section{REFERENCES}

1. Johnston SL, Lock RJ, Gompels MM. Takayasu arteritis: a review. J Clin Patho 2002; 55: 481-486.

2. Fauci AS, Braunwald E, Kasper DL, Hauser SL, Longo DL, Jameson JL, et al. Diseases of the aorta. In: Creager MA, Loscalzo J, editors. Harrison's principles of internal medicine. 17th ed. United States of America: McGraw-Hill; 2008. p.15631568.
3. Wolfe JB. Report of the Committee on nomenclature of the American Society for the Study of Arteriosclerosis. Circulation $1955 ; 12: 1065$.

4. Camilleri JP, Bruneval P. The vasculitis syndrome in aorta and large arteries. In: Camilleri JP, Berry C, Fiessinger JN, Bariety J, editors. Diseases of the arterial wall. London: Springer-Verlag; 1989. p. 457-9. 
5. Lupi-Herrera E, Sanchez-Torres G, Marcushamer J, et al. Takayasu's arteritis: clinical study of 107 cases. Am Heart J 1977;93: 94-102.

6. Ishikawa K. Natural history and classification of occlusive thromboaortopathy (Takayasu's disease). Circulation 1978;57: $27-35$.

7. Sharma BK, Sagar S, Singh AP, Suri S. Takayasu arteritis in India. Heart Vessels Suppl 1992;7:37- 43.

8. Gozal Y, Ginosar Y, Gozal D. Combined general and epidural anesthesia for a patient with Takayasu's arteritis. Reg Anesth $1995 ; 20: 246-8$.

9. Warner MA, Hughes DR, Messick JM. Anesthetic management of patient with pulseless disease. Anesth Analg 1983;62:532-5.

10. Clark AG, al-Qatari M. Anesthesia for caesarean section. Can J Anaesth 1998;45:377-9.

11. Kawaguchi M, Obsumi T, Nakajima T, Kuro M. Intraoperative monitoring of cerebral haemodynamics in patients with Takayasu's arteritis. Anaesthesia 1993;48:496-8.

12. Thorburn JR, James MF. Anaesthetic management of Takayasu's arteritis. Anaesthesia 1986;41:734-8.

13. Ramanathan S, Gupta U, Chalon J, Turndorf H. Anesthetic considerations in Takayasu's arteritis. Anesth Analg 1979;58: 247-9.
14. Herrema I. Takayasu's disease and caesarean section. Int J Obstet Anaesth 1992;1:1172-9.

15. Fawcett WJ, Razis PA, Berwick EP. Postoperative cerebral infarction and Takayasu's disease. Eur J Anaesthesiol 1993;10: 33-5.

16. Hamlyn EA, Douglass CA, Plaat F, Crowhurst JA, Stocks GM. Low-dose sequential combined spinal-epidural: an anaesthetic technique for caesarean section in patients with significant cardiac disease. Int J Obstet Anesth 2005; 14: 355361.

17. Holmstrom B, Laugaland K, Rawal N, Hallberg S. Combined spinal epidural block versus spinal and epidural block for orthopaedic surgery. Can J Anaesth. 1993; 40(7): 601-6.

18. Shrestha GS, Aryal D. Anaesthetic management of a patient with dermatomyositis and valvular heart hisease. Kathmandu Univ Med J 2012;3(2):100-102.

19. Subramaniam $K$, Shivanand $C$, Virender KA, Iqbal $R$, Venkatesh B, Navin M, et al. Anesthetic Management of Patients with Takayasu's Arteritis: A Case Series and Review. Anesth Analg 2001;93:60 -5.

20. Miekle A, Milne B. Extreme arterial blood pressure differentials in a patient with Takayasu's arteritis. Can J Anaesth 1997;44: 868-71. 